\title{
Geodetic and seismic signatures of episodic tremor and slip in the northern Cascadia subduction zone
}

\author{
H. Dragert, K. Wang, and G. Rogers \\ Geological Survey of Canada, Pacific Geoscience Centre, Sidney, B.C., V8L 4B2, Canada
}

(Received June 2, 2004; Revised December 2, 2004; Accepted December 24, 2004)

\begin{abstract}
Slip events with an average duration of about 10 days and effective total slip displacements of severalc entimetres have been detected on the deeper $(25$ to $45 \mathrm{~km})$ part of the northern Cascadia subduction zone interface by observing transient surface deformation on a network of continuously recording Global Positioning System (GPS) sites. The slip events occur down-dip from the currently locked, seismogenic portion of the subduction zone, and, for the geographic region around Victoria, British Columbia, repeat at 13 to 16 month intervals. These episodes of slip are accompanied by distinct, low-frequency tremors, similar to those reported in the forearc region of southern Japan. Although the processes which generate this phenomenon of episodic tremor and slip (ETS) are not well understood, it is possible that the ETS zone may constrain the landward extent of megathrust rupture, and conceivable that an ETS event could precede the next great thrust earthquake.
\end{abstract}

Key words: Crustal deformation, GPS, slow earthquakes, non-volcanic tremors, Cascadia margin.

\section{Introduction}

Beginning in 1992, increasing numbers of automated continuous Global Positioning System (GPS) sites have been established in southwestern British Columbia and northwestern United States in order to monitor crustal motions due to present-day tectonics. Analyses of GPS data from these sites have confirmed that long-term elastic deformation occurs along the northern Cascadia Margin due to the locking of converging plates across a portion of the subduction interface between the Juan de Fuca plate and the overlying North America (NA) plate (cf. Mazzotti et al., 2003). The motion vectors shown in Fig. 1 are based on the linear trends in the time series of changes in horizontal positions of GPS sites with respect to the reference site DRAO, located south of Penticton, British Columbia, and assumed fixed on the NA plate. The pattern of the regional crustal velocity field is a key constraint in determining the location and extent of the locked fault zone-i.e. that portion of the fault that will ultimately rupture in a great subductionthrust earthquake (cf. Wang et al., 2003). However, over the last three years it has become clear that some of the regional GPS sites located in the Cascadia forearc experience repeated periods of transient motion opposite to the longterm linear trends and these brief reversals of motion, which can be modeled by slow slip on the deeper plate interface, are accompanied by distinct seismic tremors.

\section{Geodetic Signature of ETS}

Since the discovery of "silent" slip on the Cascadia Subduction Zone (CSZ) by Dragert et al. (2001), the reexamination of past GPS data has revealed that the motions

Copy right(c) The Society of Geomagnetism and Earth, Planetary and Space Sciences (SGEPSS); The Seismological Society of Japan; The Volcanological Society of Japan; The Geodetic Society of Japan; The Japanese Society for Planetary Sciences; TERRAPUB of continuous GPS sites in northern Cascadia are marked by numerous, brief, episodic reversals. This is best illustrated by the east-component time series at the Victoria GPS site (ALBH) where the motion relative to DRAO is clearly characterized by a sloped saw-tooth function: For periods of 13 to 16 months, there is eastward motion that is more rapid than the long-term rate, followed by a 1 to 3 week period of reversed motion (see Fig. 2). The surprising regularity of these brief reversals, first pointed out by Miller et al. (2002), is summarized in Table 1 which lists the dates for the midpoints of the transients for ALBH. These dates were determined by running a 160-day, zero-mean, saw-tooth function along the de-trended east component time series of the two longest running regional GPS sites at Victoria (ALBH) and Neah Bay (NEAH). The normalized cross-correlation results (shown by the orange graph in Fig. 2) were able to resolve the mid-point of slip occurrences with a precision of $\sim 2$ days. Results for ALBH and NEAH were identical, indicating that both sites were responding to the same sequence of events.

The magnitude and direction of the surface displacements during reversals, the average linear trend for the 13 to 16 month inter-slip periods, and annual signals were estimated by regression on the north and east components. At ALBH, amplitudes for annual signals were 0.3 and $0.7 \mathrm{~mm}$ in the north and east components respectively which is an order of magnitude smaller than displacements associated with slip events. The average inter-slip linear trends were significantly greater than the secular (interseismic) trends. The recurrence interval for the transient events is $447 \pm 37$ days and the next ETS event for southern Vancouver Island is expected in September 2005. The average surface displacement is approximately $5 \mathrm{~mm}$ in a direction opposite to the longer-term deformation motion. For two of the larger (in area) transient events, time delays for the onset of the 


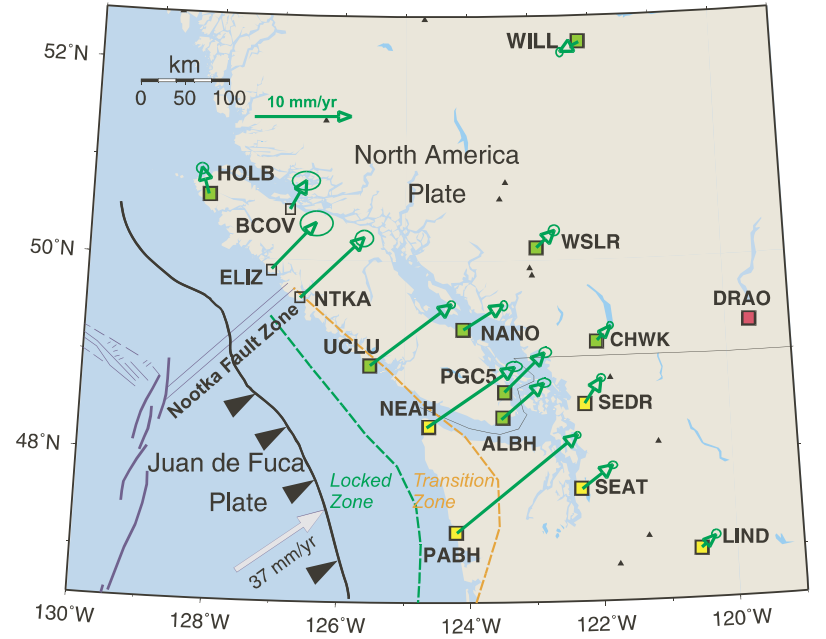

Fig. 1. Long-term velocities of regional continuous GPS sites. Three to eight-year linear trends in the horizontal position with respect to Penticton (DRAO) for some of the sites of the Western Canada Deformation Array (WCDA: green squares) and the Pacific Northwest Geodetic Array (PANGA: yellow squares) are plotted by green arrows with $95 \%$ error ellipses. The position of the strongly coupled zone determined from slip-dislocation models is indicated by the locked and transition zones. The convergence vector of the Juan de Fuca plate is with respect to the North America (NA) plate, and the GPS reference station DRAO is assumed fixed on the NA plate.

brief reversals could be resolved (Fig. 3). The July 1998 event moves out bi-directionally parallel to the strike of the subduction zone whereas the August 1999 event moves, either continuously or in steps, from the southeast to the northwest. The speed of the along-strike migration ranges from 5 to $15 \mathrm{~km}$ per day.

\section{Seismic Signature of ETS}

Prompted by the findings of non-volcanic deep tremors in southern Japan (Obara, 2002) with depths and migration velocities similar to CSZ slip events, a search of available digital records between 1997 and 2003 from sites of the Canadian Seismic Network located on southern Vancouver Island (Fig. 4(A)) revealed that tremor-like seismic signals (Fig. 4(B)) correlated temporally and spatially with the slip events (see Fig. 2). Similar to those observed in Japan, these seismic tremors are different from small earthquakes. Their spectra show a distinct absence of energy above $5 \mathrm{~Hz}$, whereas small earthquakes produce significant energy above $5 \mathrm{~Hz}$. A tremor onset is usually emergent and the signal consists of pearls of energy, often about a minute in duration. These pulsating signals may last from a few minutes to several days. Tremors appear strongest on horizontal seismographs and propagate at shear wave velocities. Tremor on an individual seismograph is unremarkable, appearing no different from transient noise due to wind or cultural sources. It is only when a number of seismograph signals are viewed together that the similarity in the envelope of the seismic signal at each site identifies the signal as ETS.

Tremor activity migrates along strike of the subduction zone in conjunction with the deep slip events at rates ranging from about 5 to $15 \mathrm{~km}$ per day. Sometimes the migration

\begin{tabular}{|c|c|c|c|c|c|}
\hline Date & $\begin{array}{l}\text { Days } \\
\text { Between } \\
\text { Transient }\end{array}$ & $\begin{array}{r}\text { Hori } \\
\text { Amount } \\
(\mathrm{mm})\end{array}$ & $\begin{array}{l}\text { rizontal D } \\
\text { t Sigma } \\
(\mathrm{mm})\end{array}$ & $\begin{array}{c}\text { Displacem } \\
\text { Azimuth } \\
\text { (Degr.) }\end{array}$ & $\begin{array}{l}\text { nents } \\
\text { Sigma } \\
\text { (Degr.) }\end{array}$ \\
\hline 09/28/94 & & 3.43 & 0.30 & -117.8 & 4.7 \\
\hline $12 / 29 / 95$ & 457 & 6.27 & 0.22 & -127.9 & 2.0 \\
\hline 05/08/97 & 496 & 5.16 & 0.22 & -111.5 & 2.2 \\
\hline 07/08/98 & 426 & 4.80 & 0.22 & -121.8 & 2.5 \\
\hline 08/26/99 & 414 & 4.62 & 0.22 & -114.9 & 2.4 \\
\hline $12 / 08 / 00$ & 470 & 5.75 & 0.27 & -118.6 & 2.5 \\
\hline 02/06/02 & 425 & 5.28 & 0.21 & -112.6 & 2.1 \\
\hline 03/03/03 & 390 & 4.99 & 0.22 & -105.6 & 2.2 \\
\hline $07 / 13 / 04$ & 498 & 4.06 & 0.30 & - 92.0 & 3.4 \\
\hline Means: & 447 & 4.93 & 0.24 & -113.7 & 2.7 \\
\hline Sigmas: & 37 & 0.80 & 0.04 & 9.7 & 0.8 \\
\hline
\end{tabular}

Secular Velocity: $5.58 \mathrm{~mm} / \mathrm{yr} \pm 0.02,51.8^{\circ} \pm 0.2$.

Inter-Slip Velocity: $9.66 \mathrm{~mm} / \mathrm{yr} \pm 0.12,57.1^{\circ} \pm 0.7$.

is gradual, but other times there is a jump from one region to another. Tremors range in amplitude and the strongest can be detected as far as $300 \mathrm{~km}$ from the source region. During an ETS event, tremor activity lasts about 10 to 20 days in any one region and contains tremor sequences that have amplitudes at least a factor of 10 larger than the minimum detectable tremor amplitude. Because of the emergent nature of the tremors, they are difficult to locate as precisely as nearby earthquakes using standard earthquake location procedures. However, using the strongest peak within correlated tremor envelopes as a common phase, these procedures produce source depths of $20 \mathrm{~km}$ to $40 \mathrm{~km}$ with uncertainties of several kilometres. Deeper solutions are in the northeast band of the forearc and better constrained solutions are near the subduction interface or just above it. The fact that surface displacement patterns have been satisfactorily modeled using simple dislocations of 2 to $4 \mathrm{~cm}$ on the plate interface bounded by the $25 \mathrm{~km}$ and $45 \mathrm{~km}$ depth contours strongly suggests a spatial correlation with the source region of tremors.

\section{Elastic Slip-Dislocation Models}

The similarity of the transient events is also shown by the similarity of simple slip-dislocation models which best fit the observations. We assume that slip occurs at the plate interface and using the subduction interface geometry from Flueck et al. (1997), the displacements observed at each site over the time of the slip are used to constrain the location, area, and amount of the slip with a trial-and-error approach. In the model, slip is assumed to be uniform over a deeper segment of the curved plate interface and linearly tapers to zero across a shallower segment immediately updip. We have also tested models that allow the slip to taper to zero over a downdip segment as well, but models without such tapering fit the GPS data either better or equally well. The zones of uniform slip and linear tapering are defined by points along margin-normal cross sections of the plate interface. We adjust the widths of the two zones by moving these points updip or downdip until the model-predicted 


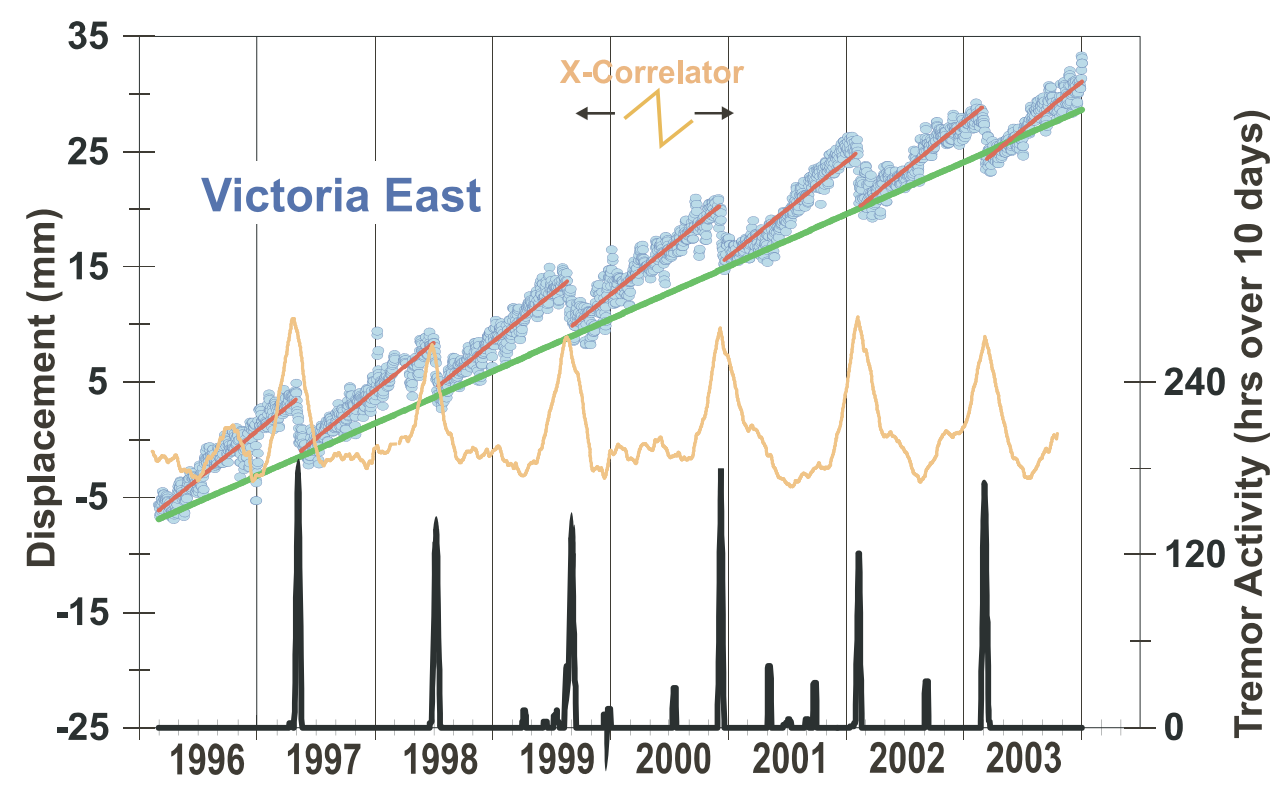

Fig. 2. Record of slip and tremor activity observed for the Victoria area. Blue circles show day-by-day change in the east component of the GPS site ALBH (Victoria) with respect to DRAO (Penticton) which is assumed fixed on the North America plate. Continuous green line shows the long-term (interseismic) eastward motion of the site. Red saw-tooth line segments show the mean elevated eastward trends between the slip events which are marked by the reversals of motion every 13 to 16 months. Orange graph shows the normalized cross-correlation obtained by cross-correlating the de-trended GPS time series with a 160-point zero-mean sawtooth segment used to determine the dates for the slip events in Table 1. Bottom graph shows the total number of hours of tremor activity observed for southern Vancouver Is. within a sliding 10-day period (complete annual records examined from 1999 onward). 10 days corresponds to the nominal duration of a slip event. Pronounced tremor activity coincides precisely with slip events.
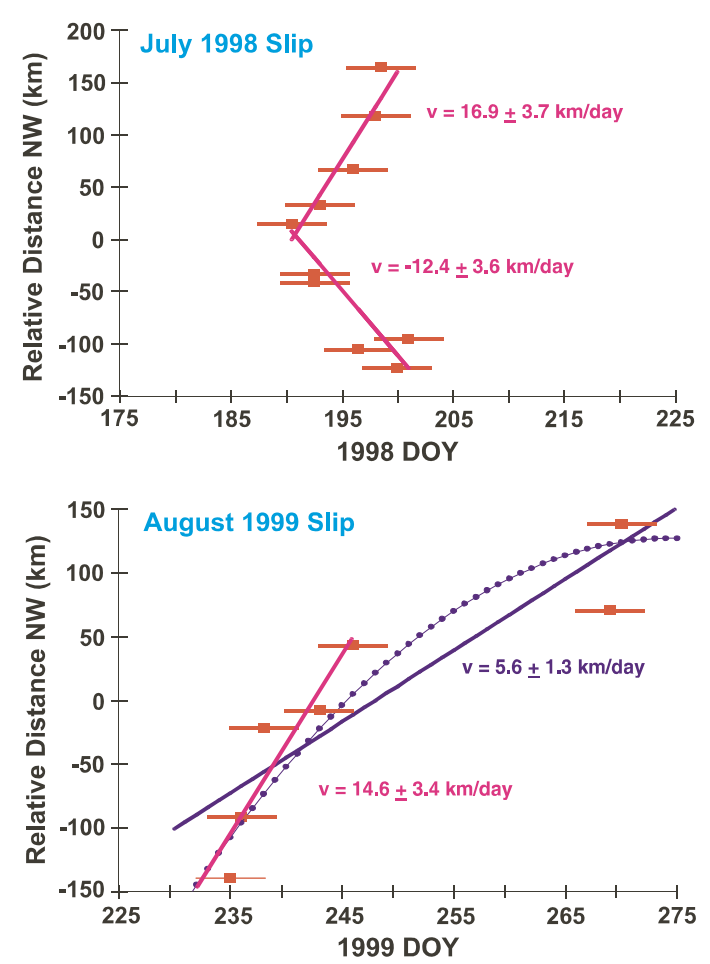

Fig. 3. Migration of transients. For the two transients affecting the widest area, the dates of occurrence (horizontal red bars) have been plotted as a function of relative site positions projected onto a NW striking line. The transients are not simultaneous at the sites. The 1998 event shows bi-directional propagation whereas the 1999 event shows uni-directional motion from SE to NW. The move-out velocity along the strike of the subduction zone averages $\sim 15 \mathrm{~km} /$ day over the first 10 days. The 1999 rupture may have slowed down or moved in distinct steps as it propagated to the $\mathrm{NW}$, making the mean propagation $\sim 6 \mathrm{~km} /$ day.
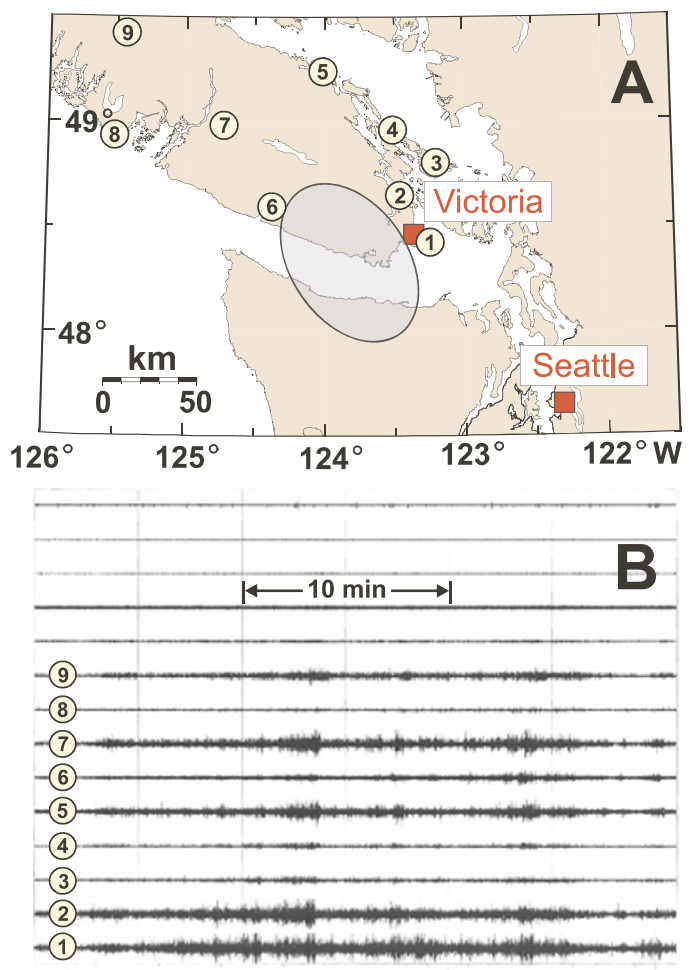

Fig. 4. (A) Map of seismic network sites (numbered circles) and approximate source region (shaded ellipse) for tremors used for correlation with observed slips. Note that both tremors and slip have been observed to migrate parallel to the strike of the subduction zone to the south, through, and to the north of this shaded region. (B) Raw sample seismic records of tremor activity at selected sites. Records have not been corrected for different gain settings at sites. It is the similarity of the envelope of the seismic signal on many seismographs that uniquely identifies tremor activity (Adapted from Rogers and Dragert, 2003). 
Jul. 1998: $3.0 \mathrm{~cm} ; M=6.8$
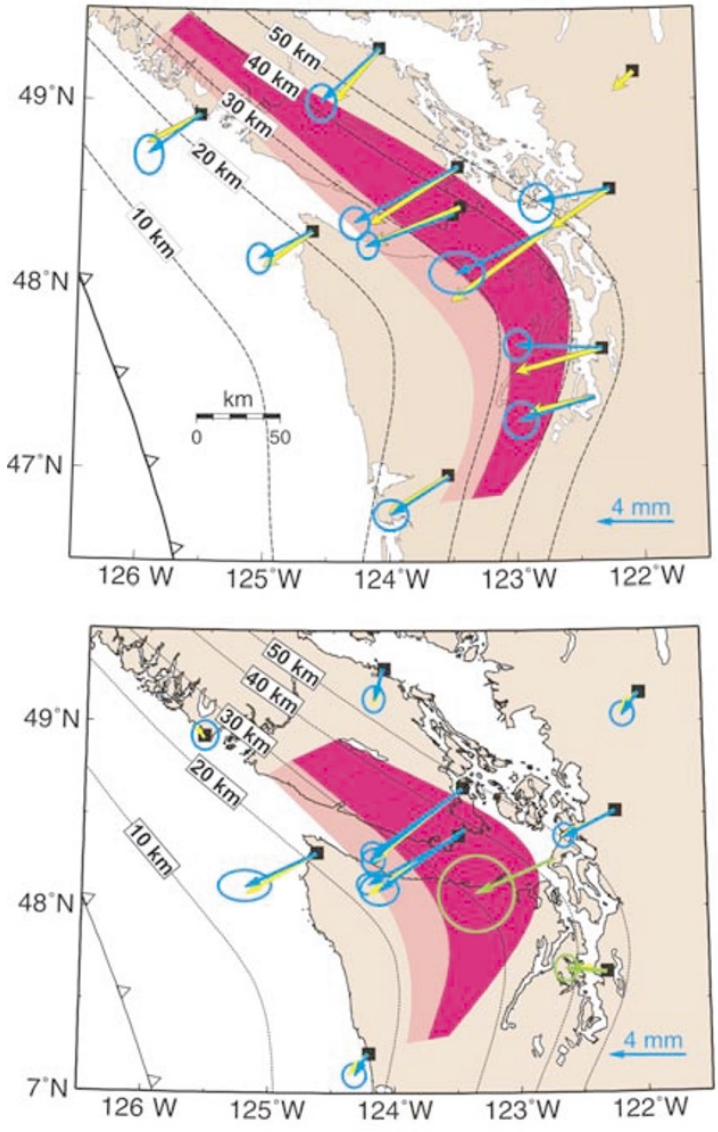

Dec. $2000: 3.0 \mathrm{~cm} ; M=6.7$
Aug. 1999: $2.3 \mathrm{~cm} ; M=6.7$
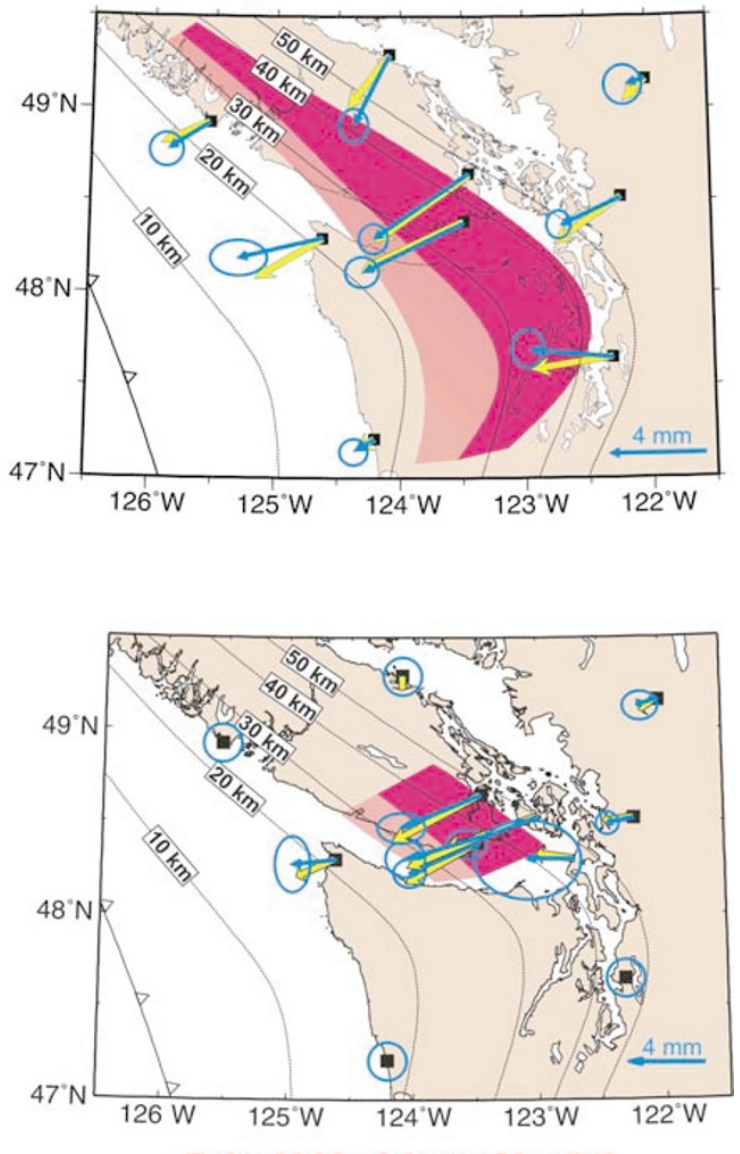

Feb. $2002: 4.0 \mathrm{~cm} ; M=6.5$

Fig. 5. Models for slow slip events. We adopt the geometry of the subducting plate interface established from structural studies (Flueck et al., 1997) and assume simple linear slip distribution directed up-dip. The four panels illustrate the results of elastic dislocation modeling (Okada, 1985) of four recent slip events. Blue arrows show observed horizontal surface displacements with $95 \%$ error ellipses that were used to constrain the models; green arrows show surface displacements obtained from separate analyses and not used in model constraint; yellow vectors show model displacements. Dark shading indicates fault areas with full slip whose magnitudes are shown in panel headers; light shading indicates fault areas where slip is tapered linearly from full to zero at the up-dip end. Also shown are equivalent moment-magnitudes assuming a rigidity of $40 \mathrm{Gpa}$.

surface displacements at most GPS stations are within the error ellipses of the observed displacements.

Figure 5 shows updated modeling results for four of these events. The good agreement between observed and modeled displacements shows that the transient motions can be represented by simple slip on the subducting plate interface between depths of 25 and $45 \mathrm{~km}$ and the slip region is parallel to the strike of the subducting plate. The downdip boundary appears to be sharper whereas the updip boundary is more diffuse, requiring a gradual tapering of the slip amplitude. Although the maximum slip is only a few centimetres per event, the large area of slip generates an equivalent moment magnitude for these "slow earthquakes" ranging from 6.5 to 6.8. A formal inversion of the GPS data could potentially resolve a more detailed slip distribution. However, because of the very few stations involved in each slip event, the inverse problem is extremely underdetermined. McGuire and Segall (2003) have used our 1999 data to test a newly developed inversion algorithm. Their solution is consistent with our simple model in terms of the average direction and magnitude of fault slip but shows large shortwavelength variations of the slip. Our uniform-slip model and their variable-slip model are end members allowed by the same GPS observations.

Better constraints for the slip distribution can be provided in the future by having strain monitoring as well as additional GPS stations. Densification of GPS coverage is required to resolve the details of the horizontal and vertical surface deformation predicted by the models (see Fig. 6). Volumetric strain due to these slips is measurable by borehole strainmeters and may also produce fluid pressure changes that can be monitored by borehole pressure sensors. Strain patterns predicted by our slip models provide important information for the planning of future strain or pressure monitoring work. In Fig. 6 we show the dilatational and shear strain predicted by our model for the 1999 slip event. Maximum contraction and shear is predicted for locations along the coastal margin with secondary maxima about 50 to $70 \mathrm{~km}$ inland. These bands of maximum strain are separated by a region of extension and minimum shear. The northern and southern ends of the displacement and strain patterns are strongly affected by model edge-effects and are not well constrained. 

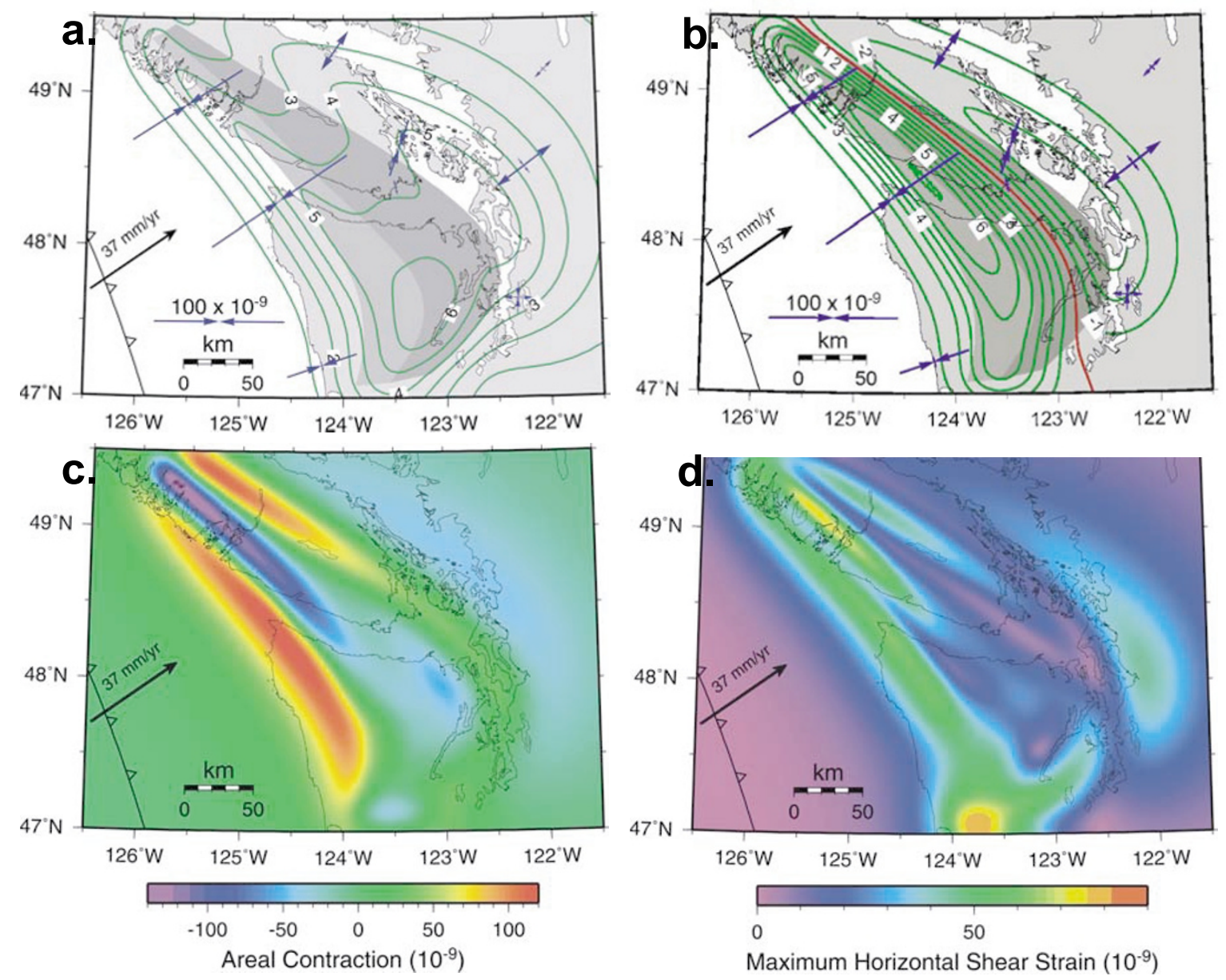

Fig. 6. Surface displacements and strain generated by slip-dislocation model for August 1999 slip event: a.) Magnitude of horizontal displacement; b.) Vertical displacement; c.) Dilatational strain; d.) Maximum shear strain. Panels (a) and (b) show displacement contours in millimetres and also principal strain components at GPS site locations. Maximum strain magnitudes are of the order of $10^{-7}$ and patterns displayed generally show a double peak. The northern and southern ends of the displacement and strain patterns are strongly affected by model edge-effects and are not well constrained.

\section{Discussion}

The horizontal motions of GPS sites in the northern Cascadia forearc are best represented by a sloped sawtooth function (SSF) and the sharper edges of the function, symptomatic of brief motion reversals, can be modeled by simple slip on the deeper subduction interface. The SSF is characterized by the long-term trend, the trends between slips, and the frequency and magnitudes of the reversals. The long-term trend is indicative of the net accumulation of stress across the locked portion of the (shallow) plate interface which is released every 500 to 600 years in a great subduction-thrust earthquake. The augmented trends between slips require temporary (13 to 16 months) stress accumulation at greater depths to account for the enhanced easterly deformation velocities which are most pronounced at inland forearc sites. Then, for reasons not yet fully understood, this stress is relieved during the episodes of "slip" causing the overlying crust to move in a direction opposite to the long-term interseismic motion over a period of one to two weeks. The episodic displacement at ALBH appears to be regular $(5 \pm 1 \mathrm{~mm}$; at an azimuth of -114 \pm 10 degrees) and does not appear to depend on the alongstrike extent of a slip episode, suggesting that the same fault area beneath ALBH is involved in each slip. This relief of stress is accompanied by distinct seismic tremors occurring on and/or above the subduction interface. Nearly periodic slip of patches of a plate boundary fault in a given time window is not uncommon. For example, numerous "repeating earthquakes" have been observed on the subduction thrust at the Japan Trench, each indicating the repeated rupture of a small fault patch surrounded by areas of stable sliding (Igarashi et al., 2003; Uchida et al., 2003).

This temporal behaviour forces a revision of kinematic constraints used for the "transition zone" in elastic slipdislocation models (Fig. 7). The long-term (inter-seismic) velocities are best modeled using an "effective" transition zone (ETZ) suggested by Wang et al. (2003). The shortterm (inter-slip) velocities require an elevated slip deficit over the deeper portion of the ETZ whose precise magnitude is not well defined, but modeling is currently underway to estimate the magnitude of transient inter-slip coupling. An average slip of $3 \mathrm{~cm}$ every 14.5 months implies a temporary slip deficit of at least $25 \mathrm{~mm} / \mathrm{yr}$ at these depths, which would account for about $2 / 3$ of the full convergence rate. The other $1 / 3$ could be accumulating over the interseismic period or could be (partly) released during minor ETS 


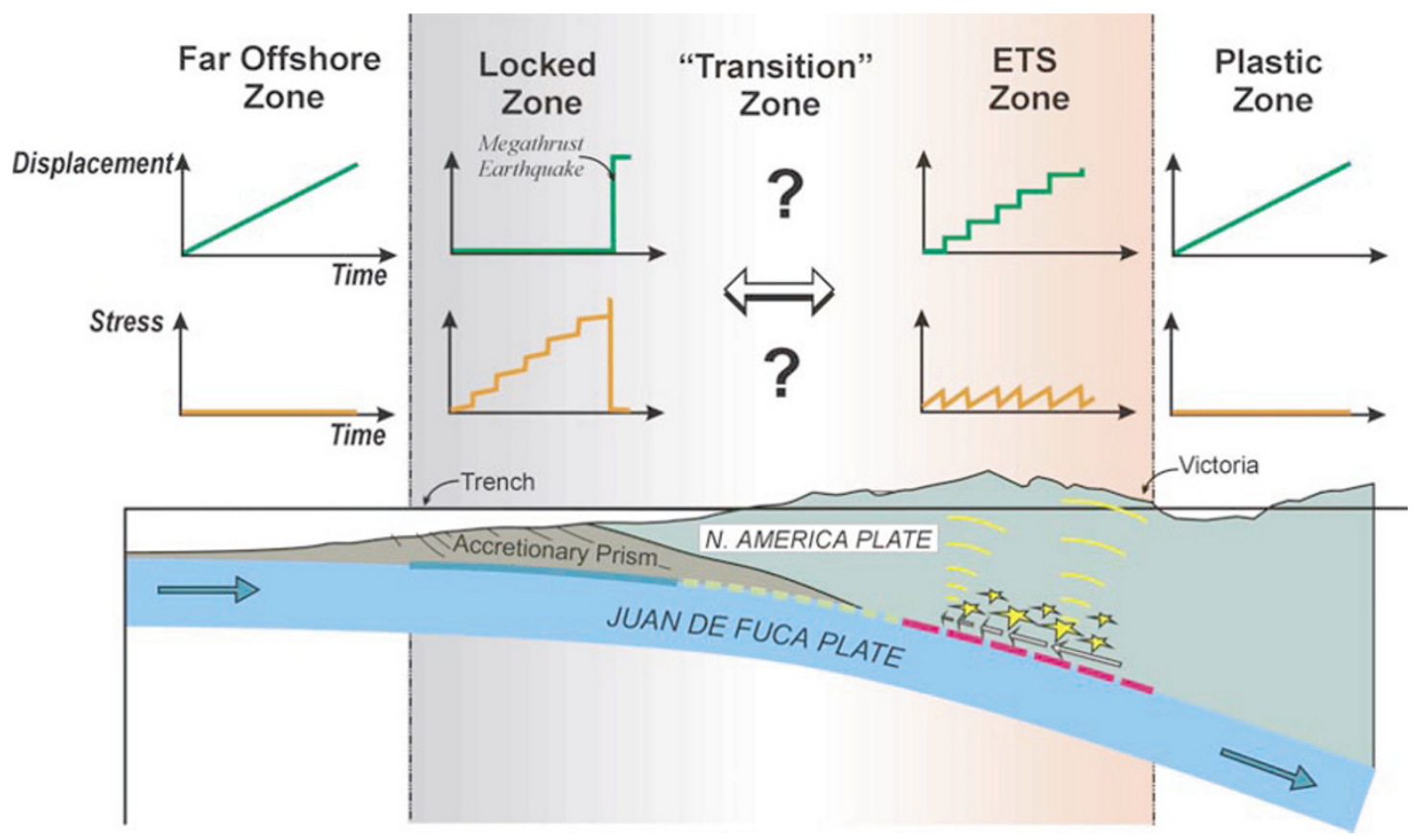

Fig. 7. Distribution of slip deficit at CSZ interface across the northern Cascadia margin. Slip-deficit rates needed for back-slip modeling of the interseismic and inter-slip surface velocities are shown schematically and are not quantitative. The nominal locked or "brittle" zone extends from (near) surface downdip to the T1 isotherm (depth $\sim 15 \mathrm{~km}$ ), and is subject to full plate-rate slip deficit. The linear transition zone used by Flueck et al. (1997) extends from the T1 to T2 isotherm (depth $25 \mathrm{~km}$ ). It was previously assumed that free slip occurred downdip from T2. Wang et al. (2003) proposed an "effective" transition zone extending from the T1 to T3 isotherm (depth $45 \mathrm{~km}$ ) whose temporal average slip-deficit is given by an exponential decay from full to zero (orange curve). This revision was required to account for the higher long-term deformation rates observed at inner margin GPS sites. The red line shows the down-dip slip deficit required during the 14.5 mo period between occurrences of slip to account for the augmented strain accumulations which are released at the time of slow earthquakes.

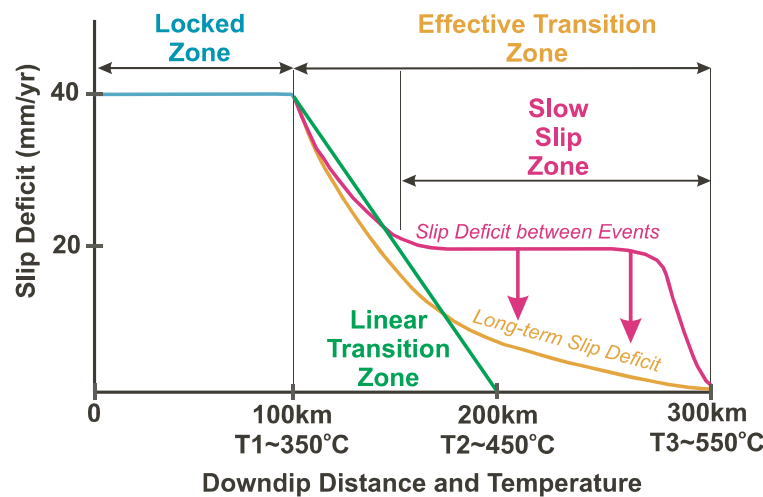

Fig. 8. Conceptual model for plate motions and stress accumulation across the CSZ interface. The permanent relative displacements and changes in shear stress across the interface are sketched as functions of time in each zone. The transition of the displacement/stress behaviour from that in the locked zone to that in the ETS zone is not well defined but may provide a new basis for defining the "transition zone". Stars represent sources of tremors that accompany slip events.

activity throughout the year, marked by observed scattered tremor activity, generally lasting less than 2 days, whose surface displacements are too small for current GPS resolution.

The kinematics described above suggest a new conceptual model for the motions and coupling across the CSZ plate interface. Figure 8 shows the displacement and stress as a function of time for the different zones on the plate interface. The displacement represented is permanent dis- placement immediately across the plate interface in the direction of convergence between the Juan de Fuca and North America plates; the stress is the incremental shear stress across the plate boundary. For the regions well offshore and for the deep zone where temperatures allow plastic behaviour, plate motions are steady at nominal plate convergent rates and no stress accumulates. Across the portion of the interface in the ETS zone, displacements occur in discrete steps and accommodate plate rates in a stair-case fashion as small amounts of stress accumulate and are repeatedly relieved. At the locked portion of the interface, no relative displacement occurs until the mega-thrust rupture. Because of the effective "stick-slip" behaviour of the ETS zone immediately downdip, stress accumulates on the locked zone in a saw-tooth fashion, not continuously as previously assumed.

Such a conceptual model has two immediate implications for regional seismic hazard: 1) the updip limit of the ETS zone may mark the downdip limit of rupture for the next megathrust earthquake; and 2) the likelihood of a megathrust earthquake is enhanced at the time of and immediately after ETS activity (Mazzotti and Adams, 2004). As illustrated in Figs. 7 and 8, the transition from the locked zone to the ETS zone is not well defined. However, it is likely that ETS activity prevents any significant long-term accumulation of stress in the ETS zone and consequently, coseismic rupture will not penetrate into this zone. Supporting this hypothesis is the example from the Nankai subduction zone (Fig. 9). The location of deep tremors as mapped by Obara (2002) delineates the downdip limit of coseismic 


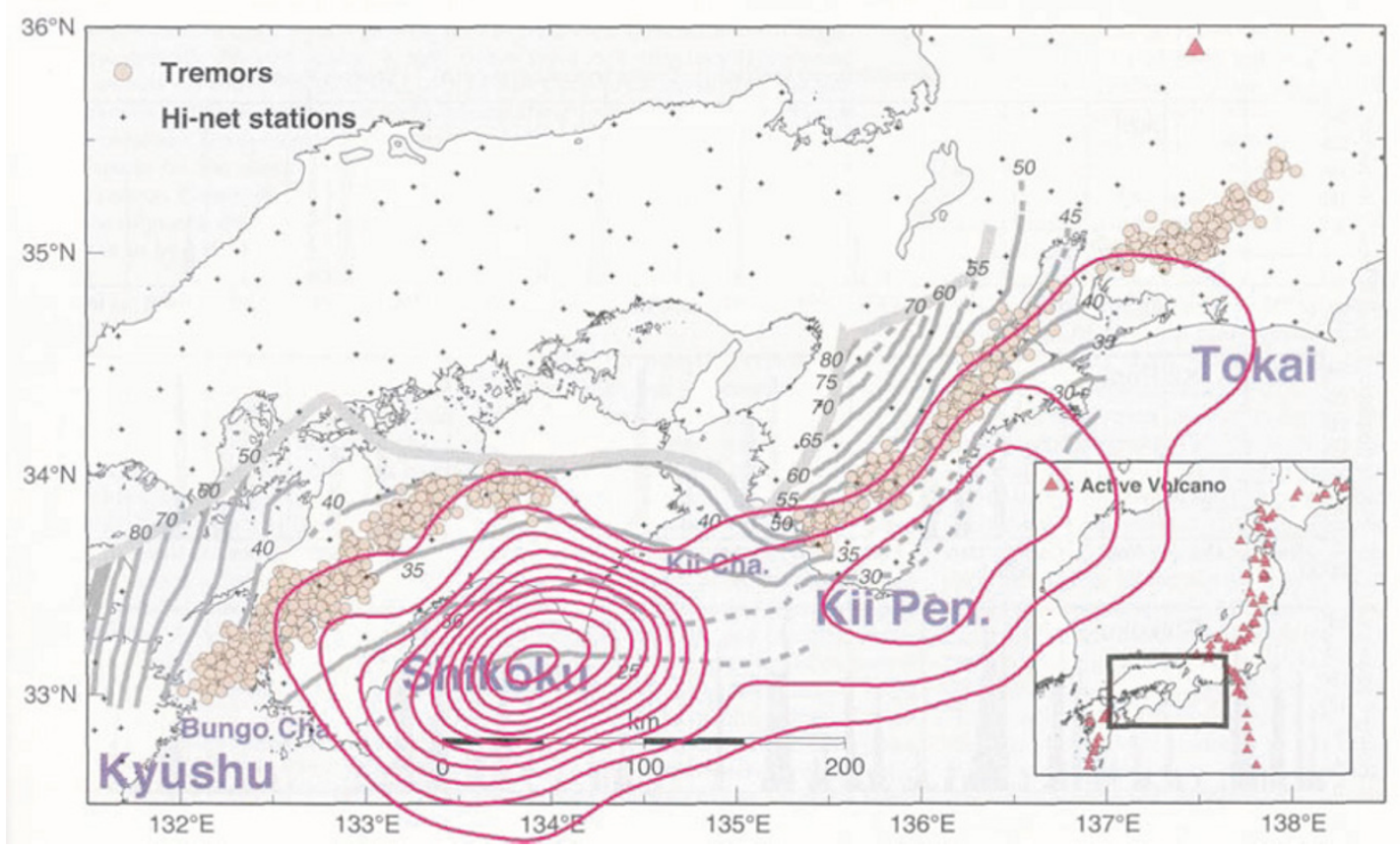

Fig. 9. Map of location of tremors and contours of coseismic slip for southern Japan. The coseismic slip distribution estimates (contours are 1 m; outer contour is the $1 \mathrm{~m}$ contour) derived by Sagiya and Thatcher (1999) for the Tonankai and Nankaido earthquakes have been overlain on a map of non-volcanic tremors published by Obara (2002). The tremors, having an average depth of $30 \mathrm{~km}$, appear to delineate the downdip extent of coseismic rupture (and possible afterslip) along the strike of the subduction zone.

rupture estimated by Sagiya and Thatcher (1999) for the 1944 Tonankai $(\mathrm{Mw}=8.1)$ and 1946 Nankaido $(\mathrm{Mw}=8.3)$ earthquakes. Sagiya and Thatcher's estimate of rupture was based on geodetic and tsunami data and therefore could include deep afterslip. A more recent estimate of the Tonankai rupture zone derived from low-gain seismograms alone (Kikuchi et al., 2003) provides even stronger evidence that tremors occur well downdip of the seismic rupture zone and therefore can act as a proxy for the landward limit of megathrust rupture.

As well as the spatial significance of the areas of slip on the CSZ interface, the repeated occurrence of slip may provide the first temporal constraint for impending earthquakes. Simple Coulomb stress calculations illustrate the transfer of stress (Fig. 10) due to episodic deep slip. The locked thrust zone directly up-dip is brought slightly closer to failure. The magnitude of the Coulomb stress increment on the locked zone is small, amounting to 0.15 bar maximum for a 2 to $3 \mathrm{~cm}$ slip. This is of the same order as stress changes induced by ocean loading at coastal margins (Cochran et al., 2004). However, for a deep slip event, not only is the Coulomb stress enhanced, but a dynamic (slow) rupture is taking place which is subsequently encouraged to propagate into the locked zone. The process of deep slip leading to a thrust earthquake is considered responsible for the $1960(\mathrm{Mw}=9.5)$ Chilean earthquake (Linde and Silver, 1989) and the 1944/46 (both Mw>8) Nankai Trough earthquakes (Linde et al., 1998). The recent discovery of slow slip in the western Tokai region of central Japan (Ozawa et al., 2002), although much longer in duration than Cascadia slip events (18 months vs. 3 weeks), supports the hypothesis of a silent event as the cause of uplifting several days before the 1944 Tonankai earthquake. Consequently, the recogni-

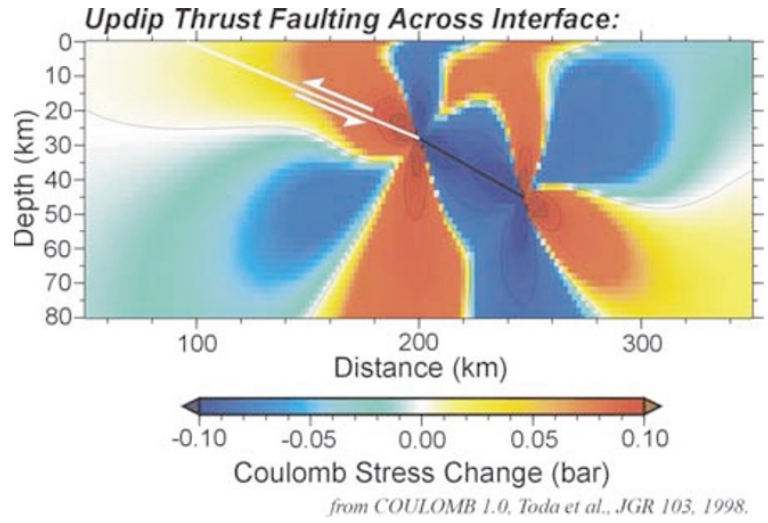

Fig. 10. Coulomb stress from $2.3 \mathrm{~cm}$ deep slip for shallow-dipping thrust. Episodic deep-slip events result in a transfer of stress to adjacent regions in discrete pulses. For the shallow-dipping megathrust zone located updip from the slip zone, each slip event brings the locked zone closer to failure. It is conceivable that one of these events may keep propagating updip and evolve into a trigger mechanism for a great subduction thrust earthquake.

tion of slip occurrence in real-time through the associated tremor activity may conceivably form the basis for timevarying seismic hazard estimates in the Cascadia region.

The processes responsible for ETS are not well understood but are strongly suspected to involve super-critical fluids (cf. Kodaira et al., 2004) and semi-brittle behaviour of materials. To date, ETS has been positively identified in only the Cascadia and the Nankai subduction zones, both of which are young and produce abundant fluids from the dehydration of metabasalts at relatively shallow depths (Hyndman and Peacock, 2003). The ETS zone beneath south- 
ern Vancouver Island also appears to correlate with a thick $(>4 \mathrm{~km})$ zone of pronounced shearwave reflectors (E-zone reflectors) that overly the subducting plate interface (Nedimovic et al., 2003) and underlie the topographic high of the Cascadia forearc. These correlations suggest that ETS could be associated with the formation of these reflectors or the mobilization of fluids in these zones. The regularity of occurrence of ETS and its along strike propagation remains unexplained.

Acknowledgments. We gratefully acknowledge the contributions of M. Schmidt, Y. Lu, and B. Schofield who maintain the GPS network operation of the WCDA. We also thank T. Sagiya and I. Kawasaki for their helpful reviews. This work was supported in part by USGS NEHRP research grant 04HQGR0047. Continuous GPS data from Washington State used in this study was provided by PANGA which is supported by NSF under Grants No. EAR-0002066, EAR-9616540, by NASA Contract No. NAG57672 , and by the USGS's NEHRP program. Geological Survey of Canada contribution 2004272.

\section{References}

Cochran, E. S., J. E. Vidale, and S. Tanaka, Earth tides can trigger shallow thrust fault earthquakes, Science, 306, 1164-1166, 2004.

Dragert, H., K. Wang, and T. S. James, A Silent Slip Event on the Deeper Cascadia Subduction Interface, Science, 292, 1525-1528, 2001.

Flueck, P., R. D. Hyndman, and K. Wang, Three-dimensional dislocation model for great earthquakes of the Cascadia Subduction zone, J. Geophys. Res., 102, 20539-20550, 1997.

Hyndman, R. D. and S. M. Peacock, Serpentization of the forearc mantle, Earth Planet. Sci. Lett., 212, 417-432, 2003.

Igarashi, T., T. Matsuzawa, and A. Hasegawa, Repeating earthquakes and interplate aseismic slip in the northeastern Japan subduction zone, $J$. Geophys. Res., 108(B5), 2249, doi:10.1029/2002JB001920, 2003.

Kikuchi, M., M. Nakamura, and K. Yoshikawa, Source rupture processes of the 1944 Tonankai earthquake and the 1945 Mikawa earthquake derived from low-gain seismograms, Earth Planets Space, 55, 159-172, 2003.

Kodaira, S., T. Iidaka, A. Kato, J. Park, T. Iwasaki, and Y. Kaneda, High pore fluid pressure may cause silent slip in the Nankai Trough, Science, 304, 1295-1298, 2004.

Linde, A. T. and P. G. Silver, Elevation changes and the great 1960 Chilean earthquake: Support for aseismic slip, Geophys. Res. Lett., 16, 1305-
1308,1989

Linde, A. T., I. S. Sacks, M. T. Gladwin, M. J. S. Johnston, and P. G. Silver, Slow earthquakes at plate boundaries-connection with large earthquakes?, EOS Transactions AGU, 79, No. 45, F600, 1998.

Mazzotti, S. and J. Adams, Variability of near-term probability for the next great earthquake on the Cascadia subduction zone, Bull. Seism. Soc. Am., 94, 1954-1959, 2004.

Mazzotti, S., H. Dragert, J. Henton, M. Schmidt, R. D. Hyndman, T. S. James, Y. Lu, and M. Craymer, Current tectonics of northern Cascadia from a decade of GPS measurements, J. Geophys. Res., 108, 2554, doi: 10.1029/2003JB002653, 2003.

McGuire, J. J. and P. Segall, Imaging of aseismic fault slip transients recorded by dense geodetic networks, Geophys. J. Int., 155, 778-788, 2003.

Miller, M. M., T. Melbourne, D. J. Johnson, and W. Q. Sumner, Periodic slow earthquakes from the Cascadia Subduction Zone, Science, 295 2423, 2002.

Nedimovic, M. R., R. D. Hyndman, K. Ramachandran, and G. D. Spence, Reflection signature of seismic and aseismic slip on the northern Cascadia subduction interface, Nature, 424, 416-420, 2003.

Obara, K., Nonvolcanic deep tremor associated with subduction in southwest Japan, Science, 296, 1679-1681, 2002.

Okada, Y., Surface deformation due to shear and tensile faults in a half space, Bull. Seismol. Soc. Am., 75, 1135-1154, 1985.

Ozawa, S., M. Murakami, M. Kaidzu, T. Tada, T. Sagiya, Y. Hatanaka, H Yarai, and T. Nishimura, Detection and monitoring of ongoing aseismic slip in the Tokai region, central Japan, Science, 298, 1009-1012, 2002.

Rogers, G. C. and H. Dragert, Episodic tremor and slip on the Cascadia Subduction Zone: The chatter of silent slip, Science, 300, 1942-1943, 2003.

Sagiya, T. and W. Thatcher, Coseismic slip resolution along a plate boundary megathrust: The Nankai Trough, southwest Japan, J. Geophys. Res., 104, 1111-1129, 1999.

Toda, S., R. S. Stein, P. A. Reasenberg, and J. H. Dieterich, Stress transferred by the $\mathrm{Mw}=6.5$ Kobe, Japan, shock: Effect on aftershocks and future earthquake probabilities, J. Geophys. Res., 103, 24543-24565, 1998.

Uchida, N., T. Matsuzawa, and A. Hasegawa, Interplate quasi-static slip off Sanriku, NE Japan, estimated from repeating earthquakes, Geophys. Res. Lett., 30(15), 1801, doi:10.1029/2003GL017452, 2003.

Wang, K., R. Wells, S. Mazzotti, R. D. Hyndman, and T. Sagiya, A revised dislocation model of interseismic deformation on the Cascadia subduction zone, J. Geophys. Res., 108, 2009-2022, 2003.

H. Dragert (e-mail: hdragert@NRCan.gc.ca), K. Wang, and G. Rogers 